\title{
Arginine Specific Aminopeptidase from Lactobacillus brevis
}

\author{
Arya Nandan, Amit Gaurav, Ashok Pandey and Kesavan Madhavan Nampoothiri * \\ Biotechnology Division; National Institute for Interdisciplinary Science and Technology; CSIR; Trivandrum- 695 \\ 019; India
}

\begin{abstract}
The proteolytic system of lactic acid bacteria contribute to the development of flavor during the ripening of cheese through the generation of short peptides and free amino acids, which directly or indirectly act as flavor precursors. Newly isolated lactic acid bacteria $(L A B)$ as well as those procured from culture collection centers were screened for the production of various substrate specific aminopeptidases. Among all the strains screened, L. brevis (NRRL B-1836) was found to produce quantifiable amount of intracellular arginine specific aminopeptidase (EC 3.4.11.6). The productivity of arginine aminopeptidase in $5 \mathrm{~L}$ fermentor was $36 \mathrm{IU} / \mathrm{L} / \mathrm{h}$. The Luedeking and Piret model was tested for intracellular production of aminopeptidase and the data seemed to fit well, as the correlation coefficient was 0.9964 for MRS. The $\alpha_{A P}$ and $\beta_{A P}$ was 0.4865 and 0.0046, respectively in MRS medium indicating that the yield was predominantly depended on growth. The culture produced lactic acid and also tolerated pH 2.0-3.0 and 0.3$0.5 \%$ bile salts, the most important probiotic features.
\end{abstract}

Key words: Lactobacillus brevis, aminopeptidases, arginine- $p$ - nitroanilide

\section{INTRODUCTION}

Aminopeptidases (EC 3.4.11) are ubiquitous enzymes widely produced in both prokaryotic and eukaryotic cells. As exopeptidases, they catalyze the cleavage of amino acids from the N-terminal position of peptides and proteins. They are involved in many biological functions such as protein maturation, protein turnover, hydrolysis of regulatory peptides, nitrogen nutrition, modulation of gene expression, etc. Consequently, they are considered as essential enzymes (McDonald and Barret 1986; Christensen et al., 1999).

Lactic acid bacteria (LAB) are characterized by their high demand for essential growth factors such as peptides and amino acids. They require additional free amino acids if a sustained maximum growth rate is to be assured, as they cannot synthesize several amino acids (Tsakaudou et al., 1993). Aminopeptidases, and more generally the proteolytic system of LAB are used as starters in food fermentation processes and are essential for the nitrogen assimilation in $\mathrm{LAB}$ and also for the development of the organoleptic properties of dairy products such as the texture and flavor (Macedo et al., 2000). In general, the concentration of free amino acids in dairy milk is insufficient to support the optimal LAB growth, and hence, the bacteria have developed complex enzyme systems such as aminopeptidases, dipeptidases and carboxy peptidases, which bring about production of small peptides and release of free amino acids starting from the large peptides in their immediate environment (Wilhelm et al., 1995; Pritchard and Coolbea, 1993; Tan, 1993). Free amino acids have direct (although probably

*Author for correspondence: madhavan85@hotmail.com 
limited) contribution to cheese flavor development, as well as an indirect contribution via formation of the afore mentioned catabolic metabolites such as amines, thiols, thioesters, aldehydes and ketones (Bibal et al., 1989). Arginine aminopeptidase (AP) could be involved both in bacterial growths by supplying amino acids, and in the development of dairy product's flavour, by hydrolyzing bitter peptides and liberating aromatic amino acids which are important precursors of aroma compounds (Yolanda and Fidel, 2002).

The modeling of microbial system is an important tool in the understanding how the system operates and how it would perform under different sets of conditions (Mohammed et al., 2007). The most widely used kinetic model for product formation in biological processes is the Luedeking-Piret model (Zeng, 1995). This model assumes that the product formation may be attributed to growth-associated and/or non growth-associated mechanisms. The non growth-associated mechanism is often considered to be conditional on maintaining the functions of cells. In the present study, attempts were made to screen $\mathrm{LAB}$ strains having substrate specific aminopeptidase activities. The study includes medium formulation and production optimization for arginine aminopetidase using $L$. brevis.

\section{MATERIALS AND METHODS}

\section{Materials}

Substrate specific $p$-Nitroanilides for L-Arginine, L-Glycine, L-Leucine-, L-Methionine, L-Proline, L-Valine and Arg-Pro $p \mathrm{NA}$ and the chromogenic substrate, $p$-nitroaniline were procured from Sigma, USA. MRS (broth/ agar) medium was from Hi- media (Mumbai, India) and all other analytical grade reagents were purchased from either Merck (Mumbai, India) or SD Fine Chemicals (Mumbai, India).

\section{Microorganisms, maintenance and inoculum preparation}

Enterococcus faecalis RKY 1, Lactobacillus brevis NRRL B-1836, Lactobacillus casei ATCC 11- 443, Lactobacillus delbrueckii NCIM 2025, Lactobacillus halotol ATCC 354108909 Lactobacillus plantarum ATCC 8014 8802, Lactobacillus pentosus ATCC 8041 and Streptococcus faecium TUB B590 were obtained from the American Type Culture collection (ATCC). Thirteen lactobacilli cultures were isolated from various sources and labeled as W3 (isolate from whey), SD1, SD2, SD3 (isolate from Sour Dough), SG1, SG2 (isolate from Snake guard), G1, G2, G3 (isolate from goat excreta) and CB1, CB2, CB3, CB5 (isolated from cabbage). All the cultures were screened for aminopeptidase activity.

The cultures were preserved by making stock solutions in $50 \%(\mathrm{v} / \mathrm{v})$ sterile aqueous glycerol and were stored at $-80{ }^{\circ} \mathrm{C}$. From this glycerol stock, the stab cultures were prepared by inoculating the cultures in MRS agar medium and incubating at $37^{\circ} \mathrm{C}$ for $48 \mathrm{~h}$. The fully grown stabs were stored at $4^{\circ} \mathrm{C}$ for routine purposes. To obtain a working culture, a loopful of stab culture was inoculated into MRS medium and grown at $37^{\circ} \mathrm{C}$ for $24 \mathrm{~h}$. The resulting culture was then transferred to fresh MRS medium and incubated for $18 \mathrm{~h}$ at $37^{\circ} \mathrm{C}$. This culture which contained $2.2 \times 10^{9} \mathrm{CFU} / \mathrm{ml}$ was used as an inoculum. Generally $2 \%(\mathrm{v} / \mathrm{v})$ inoculum was used for fermentation studies.

\section{Screening for extra and intracellular aminopeptidases}

Fermentation was carried out in 250-ml Erlenmeyer flasks with a working volume of $100 \mathrm{ml}$ MRS medium autoclaved at $121^{\circ} \mathrm{C}$ for 15 min. After cooling, the flasks were inoculated with $2 \%(\mathrm{v} / \mathrm{v})$ inoculum and incubated at $37^{\circ} \mathrm{C}$ in static condition. After the desired intervals of incubation, the samples were withdrawn as whole flasks. The fermented broths were centrifuged at 12000x g for $15 \mathrm{~min}$ at $4^{\circ} \mathrm{C}$ (Himac CR 22G, Hitachi, Japan) and both the clear supernatant and the pellets were collected. The enzymatic assay was carried out with the supernatant to determine the extra-cellular APs activity (Choi et al., 1996). The pellet was collected and washed twice with $0.1 \mathrm{M}$ potassium phosphate buffer of $\mathrm{pH}$ 7.0. After washing, the cells were dissolved in a minimum amount of the same buffer and lysozyme was added to the final concentration of $1 \mathrm{mg} / \mathrm{ml}$ and incubated at room temperature $\left(30^{\circ} \mathrm{C}\right)$ for $1 \mathrm{~h}$. The cells were then sonicated (Sonics, USA) for 5 minutes with an active time of 30 seconds cycles at $42 \%$ amplitude and the crude cell lyasate was centrifuged at $12000 \times \mathrm{g}$ for 15 minutes at $4^{\circ} \mathrm{C}$ (Tsakaudou et al., 1993). The clear cell free supernatant was collected and enzymatic assay was done to check the intra cellular enzyme activity. All the sets of experiments were carried 
out in duplicates and the average value has been reported.

\section{Aminopeptidases activity}

The aminopeptidase activities were measured using the following substrates, Arg- $p$ NA, Gly$p \mathrm{NA}$, Leu- $p \mathrm{NA}$, Met- $p \mathrm{NA}$, Pro- $p \mathrm{NA}$ and Val$p$ NA. These were dissolved to a concentration of $2.5 \mathrm{mM}$ in $50 \mathrm{mM}$ Tris- $\mathrm{HCl}$ buffer (pH7.6). Dipeptidyl aminopeptidase activity was determined using Arg-Pro- $p$ NA dissolved to the concentration of $1 \mathrm{mM}$ in the same buffer. The aminopeptidase assay was carried out as described earlier by Tan and Konings (1990) with slight modifications. The reaction mixture contained $100 \mu \mathrm{l}$ of $2.5 \mathrm{mM}$ selected substrate, $100 \mu \mathrm{L}$ of 50 $\mathrm{mM}$ Tris- $\mathrm{HCl}$ buffer $(\mathrm{pH} 7.6)$ and $50 \mu \mathrm{L}$ of the properly diluted crude enzyme extract. The wellmixed solution was incubated at $37^{\circ} \mathrm{C}$ for $15 \mathrm{~min}$ (Fernandez-Espla et al., 1997). The reaction was stopped by the addition of $100 \mu \mathrm{L}(30 \%)$ glacial acetic acid and the absorbance was measured at $405 \mathrm{~nm}$ in a microplate reader (Yolanda and Fidel, 2002) (Bio-Rad, Model 680 XR). The concentration of $p$-Nitroaniline released was calculated from a calibration curve. One International Unit (IU) of enzyme activity was defined as the amount of enzyme that releases 1 $\mu \mathrm{mol}$ of $p$-nitroaniline from 4-Nitroanilide derivatives of different substrates per minute per $\mathrm{ml}$ under the specified assay conditions. The protein concentration was determined either by Lowry method using BSA as standard (Lowry et al., 1951) or in Nanodrop spectrophotometer (ND1000) at A280 nm.

\section{Medium formulation and optimization}

Initially, the growth of the culture was monitored in MRS medium using $2 \%(\mathrm{v} / \mathrm{v})$ inoculum $\left(2.2 \times 10^{9} \mathrm{CFU} / \mathrm{ml}\right.$.) of $18 \mathrm{~h}$ old culture. At desired interval of time, samples were removed and plated after serial dilution. Growth was recorded as $\mathrm{CFU} / \mathrm{ml}$. By keeping the dextrose $(2 \%$ w/v $)$ originally present in the MRS medium as control, the different carbon sources such as fructose, maltose, sucrose, lactose, starch, cellulose and glycerol were supplemented individually in MRS medium to study their effect on enzyme production in L. brevis. Similarly, by keeping the ammonium citrate $(0.2 \% \mathrm{w} / \mathrm{v})$ used in the basal medium as a control and $0.2 \%(\mathrm{w} / \mathrm{v})$ of nitrogen sources such as ammonium sulphate, ammonium nitrate, ammonium dihydrogen ortho-phosphate, ammonium molybedate, ammonium chloride, ammonium bicarbonate, sodium citrate and urea were tried to find the efficacy of each nitrogen source for enhanced arginine-AP production in $L$. brevis. To study the effect of different inoculum size, the size was varied $(0.5,1,2,3$ and $4 \% \mathrm{v} / \mathrm{v})$. The age of the inoculum was maintained as $18 \mathrm{~h}$. A time course study $(12,15,16,18$ and $21 \mathrm{~h})$ was conducted with L.brevis to find out the optimum incubation period for maximum arginine aminopetidase production.

\section{Batch Fermentation in $5 \mathrm{~L}$ bioreactor}

For scale-up studies, the medium was sterilized at $121^{\circ} \mathrm{C}$ for $15 \mathrm{~min}$ in a $5 \mathrm{~L}$ stirred tank bioreactor (Biostat B-5; B. Braun Biotech-Sartorius) with $3 \mathrm{~L}$ working volume. L. brevis $2 \%(\mathrm{v} / \mathrm{v}), 18 \mathrm{~h}$ old was used as inoculum. The culture was agitated at 60 rpm.The initial $\mathrm{pH}$ was set at 6.2 and temperature was maintained at $37^{\circ} \mathrm{C}$. The flow rate of sparged air was $0.5 \mathrm{vvm}$. The fermentation was carried out for $24 \mathrm{~h}$. The samples were withdrawn at regular intervals and the lactic acid production, utilization of sucrose and arginine aminopeptidase production was determined. The growth was monitored by determining the dry weight of the biomass and the cell density was counted by haemocytometer.

A kinetic model for the product formation rate was described by Luedeking and Piret (Luedeking and Piret, 1959).The model illustrated an empirical relationship between the rate of product formation and the rate of cell growth measured by optical density, which was originally applied to lactic acid production from Lactobacillus delbrueckii growing in MRS medium.

$\mathrm{dP} / \mathrm{dt}=\alpha \mathrm{dX} / \mathrm{dt}+\beta \mathrm{X}$

Where, $\mathrm{X}$ was the bacterial concentration, $\mathrm{P}$ represented the product concentration, $\alpha$ and $\beta$ were empirical constants were determined from the plot of specific rate of lactic acid synthesis as a function of the specific rate of bacterial growth during batch fermentations at the given $\mathrm{pH}$, and $\mathrm{t}$ (fermentation time). The term $(\alpha \mathrm{dX} / \mathrm{dt})$ was referred to as the product formation rate associated with growth and describes the additional product formation by the growing organism; $\beta \mathrm{X}$ was the product formation rate associated with nongrowth. 


\section{Probiotic features of $\boldsymbol{L}$. brevis}

Few probiotic features were evaluated by checking the tolerance of the cultures to varying concentrations of salt, phenol and bile salt in MRS broth. Growth at $37^{\circ} \mathrm{C}$ at different medium $\mathrm{pH}$ (2.5, 3, 4 and 5), $\mathrm{NaCl}$ concentration $(4,5,8$ and $12 \%$ (w/v), phenol level $(0.2-0.5 \mathrm{~g}$ phenol $/ 100 \mathrm{ml})$ and bile salt concentrations $(0.3,0.5$ and $0.8 \mathrm{~g}$ sodium taurocholate $/ 100 \mathrm{ml}$ ) was monitored at 620 $\mathrm{nm}$ after $24 \mathrm{~h}$.

\section{RESULTS AND DISCUSSION}

Screening of LAB for aminopeptidases activity The strains were tested for the extracellular aminopeptidases activity with different substrate specificity as describe above. Most of these strains did not produce extracellular enzyme activity (data not shown). However, as shown in Table 1, there were considerable amount of intracellular enzyme activity in many of them. Although there are some studies on intacellular and extracellular aminopeptidase activities (Shihata et al., 2000), several reports (El Soda et al., 1978, Kolstad and Law, 1985) have described that aminopeptidases were intracellular enzymes that were released or leaked when the cells were lysed or damaged.Extracellular arginine aminopeptidase from Streptococcus gordonii has been reported by Goldstein et al, (2002).

Table 1 - Specific activity (IU/mg) of different intracellular aminopeptidases from LAB

\begin{tabular}{|c|c|c|c|c|c|c|c|}
\hline Cultures & Arg- $p$ NA & Pro- $p$ NA & Leu- $p$ NA & Met- $p$ NA & Gly-pNA & Val-pNA & Arg-Pro-pNA \\
\hline L. brevis & & & & & & & \\
\hline NRRL B-1836 & 0.0366 & 0.0007 & 0.0003 & 0 & 0 & 0 & 0 \\
\hline L. casei & & & & & & & \\
\hline ATCC 11-443 & 0.0248 & 0.0002 & 0.0948 & 0.0248 & 0 & 0.0135 & 0.0173 \\
\hline L. delbrueckii & & & & & & & \\
\hline NCIM 2025 & 0.0159 & 0 & 0.0062 & 0 & 0 & 0 & 0.0011 \\
\hline L. plantarum ATCC & & & & & & & \\
\hline 80148802 & 0.0428 & 0 & 0.0086 & 0.0023 & 0 & 0 & 0.0062 \\
\hline L. pentosus ATCC & & & & & & & \\
\hline $\begin{array}{l}8041 \\
\text { L. halotol }\end{array}$ & 0.0226 & 0 & 0.0041 & 0 & 0.0003 & 0 & 0.0022 \\
\hline $\begin{array}{l}\text { ATCC } 35410 \\
\text { E. faecalis }\end{array}$ & 0.0273 & 0 & 0.0058 & 0.0021 & 0 & 0 & 0.0019 \\
\hline $\begin{array}{l}\text { RKY } 1 \\
\text { S. faecium }\end{array}$ & 0.0347 & 0 & 0.0082 & 0 & 0 & 0 & 0 \\
\hline TUB B 590 & 0.0221 & 0 & 0.0035 & 0.0009 & 0 & 0 & 0 \\
\hline W 3 & 0.0289 & 0.0012 & 0.0618 & 0.0183 & 0 & 0.0093 & 0.0096 \\
\hline MC 1 & 0.0124 & 0 & 0.0041 & 0.0012 & 0 & 0 & 0.0003 \\
\hline CB 1 & 0.0095 & 0 & 0.0042 & 0 & 0 & 0 & 0 \\
\hline SG 2 & 0.011 & 0 & 0.0031 & 0 & 0 & 0 & 0 \\
\hline
\end{tabular}

The results indicated that among different LAB bacteria showing APs activity, $L$. brevis and $L$. plantarum showed comparatively higher specific activity for arginine-AP but since all other APs (leucine, proline, methionine, glycine, valine and the dipeptidase arg-pro) activity were either less or negligible in L.brevis than L. plantarum and it could make the downstream processing of the arginine-AP easier and it could also improve the substrate specificity. Therefore $L$. brevis was selected for further study.
Macedo et al., (2003) showed that Arg $p$ NA, Leu $p \mathrm{NA}$ and Lys $p$ NA were the substrates hydrolysed at the highest rate (under the condition of saturation by substrate) by cell free extracts (CFE) of Lactobacillus paracasei ESB 230 and Leuconostoc mesenteroides ESB 136, whereas Met pNA and Arg $p$ NA were the substrates more rapidly taken up by CFE of Lactobacillus lactis ESB 117 and Enterococcus faecium ESB 50. Intracellular aminopeptidase activities from $L$. brevis ATCC 14869 cells for pro pNA substrate 
has been reported by Miia et al., (2002).

Effect of carbon source and other parameters on Arginine-aminopeptidase activity

As shown in Fig.1, the specific activity for arginine-AP was maximum (0.064) using sucrose as carbon source. The enzyme activity was relatively low in the case of cellulose and no activity in case of glycerol. In the case of nitrogen sources, the maximum enzyme activity was with ammonium citrate which was the nitrogen source used in the control as shown in Table 2. There were reports dealing with inorganic nitrogen sources such as ammonium sulphate and ammonium citrate giving better protease yields in some organisms (Wellingta and Martins, 2004). Regarding the inoculum size, there was not much difference in specific activity of enzyme while using different inoculum sizes as shown in Table 2. Hence, $2 \%(\mathrm{v} / \mathrm{v})$ was used for further studies.

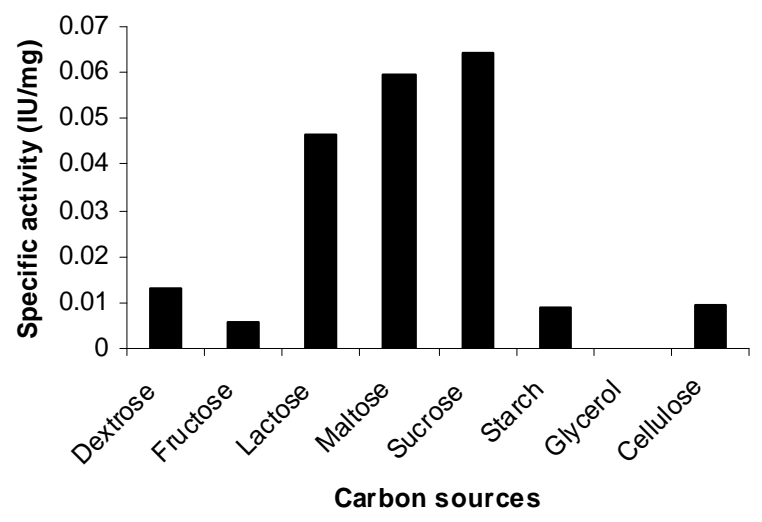

Figure 1 - Effect of different carbon sources on arginine aminopeptidase production by L. brevis

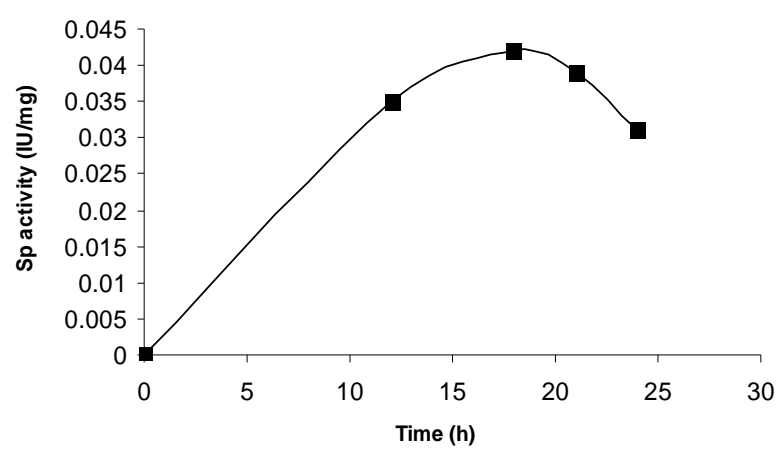

Figure 2 - Time course study on arginine aminopeptidase production.

Table 2 - Effect of different nitrogen sources and inoculum size on arginine-AP production by L.brevis

\begin{tabular}{llll}
\hline Nitrogen source $(\mathbf{0 . 2 \%}, \mathbf{w} / \mathbf{v})$ & Specific activity & Inoculum size $(\boldsymbol{\%}, \mathbf{v} / \mathbf{v})$ & Specific activity \\
\hline Ammonium citrate & $\mathbf{0 . 0 5 6 9}$ & 0.50 & 0.0585 \\
Ammonium sulphate & 0.0512 & 1 & 0.0441 \\
Ammonium nitrate & 0.0377 & 2 & 0.0456 \\
Ammonium dihydrogen ortho- phosphate & 0.0513 & 3 & 0.0469 \\
Ammonium molybedate, & 0.0468 & 4 & 0.0429 \\
Sodium nitrate & 0.0388 & & \\
Urea & 0.0463 & & \\
Ammonium bicarbonate & 0.0353 & & \\
Ammonium chloride & 0.0472 & & \\
\hline
\end{tabular}


During the time course study to monitor the enzyme activity, the maximum specific activity was recorded after $16 \mathrm{~h}$ of growth $(0.042 \mathrm{IU} / \mathrm{mg}$ protein) (Fig.2).

\section{Batch fermentation in 5-L fermenter}

The growth pattern of L. brevis in MRS medium is shown in Fig. 3. The distinct feature of cells grown in MRS media was a short lag phase of about 3 to $6 \mathrm{~h}$ (Fig. 3). The culture almost immediately entered the exponential phase and reached the stationary phase in $18 \mathrm{~h}$ at a biomass concentration of $2.285 \mathrm{~g} / \mathrm{L}$ and a cell count of $32 \times 10^{8} \mathrm{CFU} / \mathrm{ml}$ (Fig. 3).

The fermentation profile of $L$. brevis grown in
MRS medium in $5 \mathrm{~L}$ fermentor is shown in Fig. 4. The pattern of biomass change was comparable with that of cell density count. Lactic acid concentration of $20.42 \mathrm{~g} / \mathrm{L}$ was obtained in $24 \mathrm{~h}$ (Fig. 4). The initial sucrose concentration in the medium was $20 \mathrm{~g} / \mathrm{L}$. At the onset of the stationary phase, sucrose was almost utilized and the lactic acid production was about to cease. Lactic acid has been reported to inhibit the cell growth, but other environmental factors could also involve in growth inhibition (Christensen et al., 1999). The cell counts were maximum after $24 \mathrm{~h}$ as shown in Fig. $3\left(54 \times 10^{8} \mathrm{CFU} / \mathrm{ml}\right)$ and biomass concentration was $2.45 \mathrm{~g} / \mathrm{L}$ (Fig. 4).

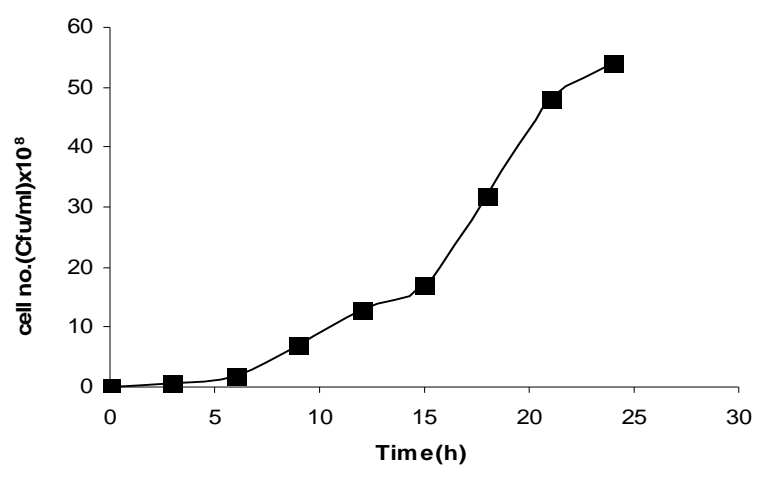

Figure 3 - Growth pattern of L. brevis in MRS medium.

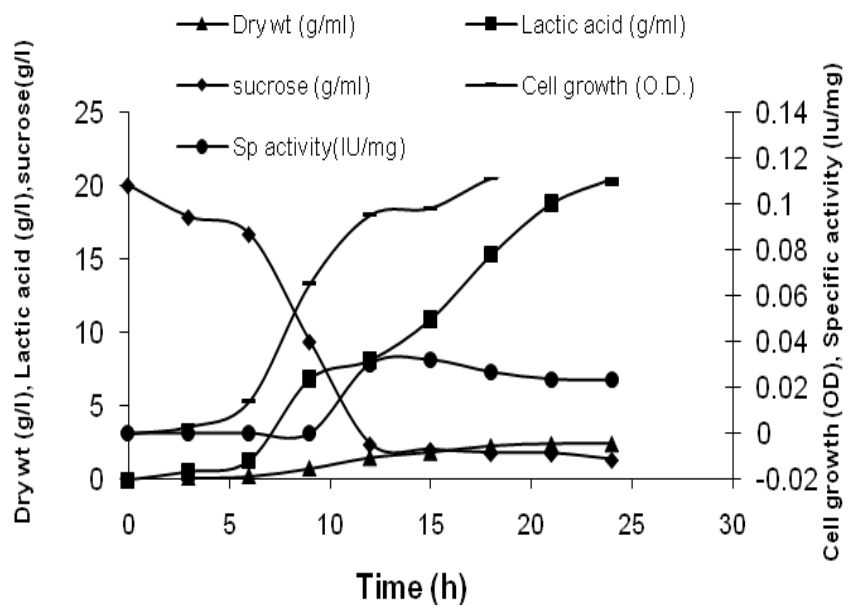

Figure 4 - Fermentation profile in 5-L batch fermenter for arginine-aminopeptidase production by L. brevis. 
The productivity of arginine-aminopeptidase in fermentor was $36 \mathrm{IU} / \mathrm{L} / \mathrm{h}$. The maximum specific growth rate of the culture grown in MRS was 0.046 per $h$ and this was reached in $18 \mathrm{~h}$, indicating fast growth in MRS medium. The maximal specific rate of substrate utilization in MRS medium was $0.033 / \mathrm{h}$. The biomass yield coefficient on substrate was 0.131

The kinetics of growth and lactic acid production for Lactobacillus sp. has been described earlier by Luedeking and Piret (1959). The coefficients given by the Luedeking and Piret model were determined from the plot of specific rate of lactic acid synthesis as a function of the specific rate of bacterial growth during batch fermentations at the given $\mathrm{pH}$ 4.2. In the present study for the estimation of parameters, only data from the exponential and stationary phases were included because no meaningful information was obtained from the lag phase data. For MRS medium in lactic acid production, the $\alpha_{L A}$ was 1.3045 and $\beta_{L A}$ was 0.0138 ; correlation was 0.9989 . The value of $\alpha_{L A}$ was higher than $\beta_{L A}$ as lactic acid production was an energy dependent pathway and thus associated with growth. Kemp et al., (1989) have also reported high value for $\alpha_{L A}$ than $\beta_{L A}$. Luedeking and Piret had reported that for Lactobacillus grown in MRS medium, $\alpha$ and $\beta$ values were also dependent on the $\mathrm{pH}$ of the growth medium. The Luedeking and Piret model was also tested for intracellular production of aminopeptidase. The data seemed to fit well, as the correlation coefficient was 0.9964 for MRS. The $\alpha_{\mathrm{AP}}$ and $\beta_{\mathrm{AP}}$ were 0.4865 and 0.0046 , respectively in MRS medium. The aminopeptidase production was predominantly associated with growth although a small portion could be attributed to metabolism not associated with the growth. The increased production of aminopeptidase led to the hydrolysis of the available peptides into amino acids, which supply the cells with sufficient amounts of amino acids for cell synthesis.

\section{Probiotic characteristics}

L. brevis culture was checked for the tolerance to $\mathrm{NaCl}$, low $\mathrm{pH}$, bile salt, and phenol. The strain had tolerance towards $\mathrm{NaCl}$ (4 \%, OD 1.634 at $600 \mathrm{~nm}), \mathrm{pH}(2-3$, OD 0.03 at $660 \mathrm{~nm})$, low phenol level $(0.3 \%$, OD. 1.359 at $660 \mathrm{~nm})$ and bile salt $(0.5 \%$, OD 0.998 at $660 \mathrm{~nm})$. According to Pancheniak and Soccol (2005), the strains that showed $0.3 \%$ tolerance to bile could be used as probiotic for swine. This was found to be an added advantage of this strain. In a study by Ronka et al., (2003) concluded that L. brevis was claimed as a promising candidate as a probiotic supplement in dairy products.

\section{CONCLUSION}

An over view of the aminopeptidase profiles of selected strains of lactic acid bacteria showed the presence of substrate specific intracellular aminopeptidase activity, including arginine amino peptidases. Using L.brevis NRRL B-1836 the maximum production of this enzyme was obtained at a late exponential phase. This knowledge and the screening of new LAB strains which perform better may provide healthy food with appealing texture and flavor.

\section{ACKNOWLEDGEMENT}

One of the authors (AN) is deeply indebted to Kerala State Council for Science Technology and Environment (KSCSTE) for the award of Research Fellowship for doctoral studies. Authors are also thankful to grant from CSIR network project (NWP 006).

\section{REFERENCES}

Bibal, B., Kapp, C.M., Goma, G., Pareilleux, A. (1989), Continuous culture of Streptococcus cremoris on lactose using various medium conditions. Appl. Microbiol. Biotechnol., 32, 155.

Choi, H., Laleye, L., Amantea, G.F., Simard, R.E. (1996), Production of Aminopeptidase from Skim Milk Whey Permeate Medium by Lactobacillus casei ssp. casei. J. Dairy. Sci., 79, 956-963.

Christensen, J.E., Dudley, E.G., Pederson, J. A., Steel, J.L. (1999), Peptidases and amino acid catabolism in lactic acid bacteria. Antonie van Leeuwenhoek., 76, 217-246.

El Soda, M., Desmazeaud, M.J., Bergere, J.L. (1978), Peptide hydrolases of Lactobacillus casei: isolation and general properties of various peptidase activities. J. Dairy. Res., 45, 445.

Fernandez-Espla, M.D., Martin-Hernandez, M.C., Fox, P.F. (1997), Purification and characterization of a prolidase from Lactobacillus casei subsp. casei IFPL 731. Appl. Environ. Microbiol., 63, 314-316. 
Goldstein, J.M., Nelson, D., Kordula, T., Mayo J. A., Travis, J., (2002), Extracellular arginine aminopeptidase from Streptococcus gordonii FSS2. Infect. immun., 70, 836-843.

Kemp, T.T., Karim, K.M., Linden, J.C., Tenaerdv, R.P. (1989), Response surface optimization of Lactobacillus plantarum batch growth. Biotechnol. Lett., 11, 817.

Kolstad, J., Law, B.A. (1985), Comparative peptide specificity of cell wall, membrane and intracellular peptidases of group N. streptococci, J. Appl. Bacteriol., 58, 449.

Luedeking, R., Piret, E.L. (1959), Kinetic study of the lactic acid fermentation. Batch process at controlled pH. J. Biochem. Microbiol. Technol., Eng. 1, 393.

Lowry, O., Rosebrough, N., Farr, A., Randall, R. (1951), Protein measurement with the folin phenol reagent. J. Biol. Chem., 193, 251.

Macedo. A.C., Marta. V., Raquel. P., Malcata. F.X. (2000), Peptide hydrolase system of lactic acid bacteria isolated from Serra da Estrela cheese. Int. Dairy. J., 10, 769-774.

McDonald, J.K., Barret, A.J. (eds.) (1986), Mammalian proteases: a glossary and bibliography. Exopeptidases. 2, Academic Press, London.

Miia J.V., Silja A.J., Paul, M., Uwe B.S., Airi, P. (2002), Isolation of Three New Surface Layer Protein Genes (slp) from Lactobacillus brevis ATCC 14869 and Characterization of the change in their expression under aerated and anaerobic conditions. J. Bacteriol., 184, 6786-6795.

Mohammad, F., El-Tayeb, O., Aboulwafa, M. (2007), Optimization of the industrial production of bacterial $\alpha$ amylase in Egypt. V. Analysis of kinetic data for enzyme production by two strains of Bacillus amyloliquefaciens. Afr. J. Biotechnol., 7, 4537-4543.

Pancheniak, E.R., Soccol, C.R. (2005), Biochemical characterization and identification of probiotic Lactobacillus for swine. B.CEPPA Curitiba, 23, 299310.

Pritchard, G. G., Coolbear, T. (1993), The physiology and biochemistry of the proteolytic system in lactic acid bacteria. FEMS Microbial. Rev., 12, 179-206.
Ronka, E., Malinen, E., Saarela, M., Rinta-Koski, M., Aarnikunnas, J., Palva, A. (2003), Probiotic and milk technological properties of Lactobacillus brevis. Int. Food. Microbiol., 83, 63-74.

Shihata, A., Shah, N.P. (2000), Proteolytic profiles of yogurt and probiotic bacteria. Int. Dairy. J., 10, 401408.

Tan, P.S.T., Konings, W.N. (1990), Purification and characterization of an aminopeptidase from lactococcus lactis subsp. cremoris wg2. Appl. Environ. Microbiol., 56, 526-532.

Tan, P.S.T., Poolman, B., Konings, W.N. (1993), The proteolytic enzymes of Lactococcus lactis. J. Dairy Res., 60, 269-286.

Tsakaudou, E., Dalezios. I., Georgalaki, M., Kalantzopoulos, G. (1993), A comparative study: aminopeptidase activities from lactobacillus delbrueckii ssp. bulgaricus and streptococcus therrnophiius. J. Dairy. Sci., 76, 2145-2151.

Wellingta do. N., Martins, M.L.L. (2004), Production and properties of an extracellular protease from thermophilic Bacillus species. Braz. J. Microbiol., 35, 91-96.

Wilhelm, B., Hans-Peter, B., Sonja, L., Knut, H. (1995), Purification and characterization of a new tripeptidase from Lactobacillus delbrueckii ssp. Bulgaricus B14. Int. Dairy. J., 5, 493-502.

Yolanda, S., Fidel, T. (2002), Purification and characterization of an arginine aminopeptidase from Lactobacillus sakei. Appl. Environ. Microbiol., 68, 1980-1987.

Zeng A.P. (1995), A Kinetic model for product formation of microbial and mammalian cells. Biotechnol. Bioeng., 46, 314.
Received: September 23, 2009; Revised: February 24, 2010; Accepted: September 22, 2010. 